\title{
Effect of Hyperglycemia on Erythrocyte Carbonic Anhydrase and Lactic Acid in Type II Diabetic Subjects
}

\author{
Salihu Ismail Ibrahim ${ }^{1,2}$, Ameh Danladi Amodu², Atawodi Sunday Ene-0jo², Umar Alhaji \\ Ismaila $^{2}$, Mohammed Fakhruddeen ${ }^{3}$ \\ ${ }^{1}$ Department of Biochemistry, Federal University, Dutse, Nigeria \\ ${ }^{2}$ Department of Biochemistry, Ahmadu Bello University, Zaria, Nigeria \\ ${ }^{3}$ Department of Endocrinology, Mohammed Abdullahi Wase Specialist Hospital, Kano, Nigeria \\ Email: "salihuringim@yahoo.com
}

Received 19 March 2016; accepted 3 May 2016; published 6 May 2016

Copyright (C) 2016 by authors and Scientific Research Publishing Inc.

This work is licensed under the Creative Commons Attribution International License (CC BY). http://creativecommons.org/licenses/by/4.0/

(c) (i) Open Access

\begin{abstract}
Background: Carbonic anhydrase (CA) is a ubiquitous enzyme catalyzing the reversible hydration of $\mathrm{CO}_{2}$ to $\mathrm{HCO}_{3}^{-}$and $\mathrm{H}^{+}$. CA plays a crucial role in $\mathrm{CO}_{2}$ transport, acid-base balance, and in linking local acidosis to $\mathrm{O}_{2}$ unloading from hemoglobin and also facilitates lactate shuttling across the monocarboxylate transporters (MCT). The study aimed to investigate the influence of hyperglycemia on erythrocyte carbonic anhydrase activity and lactic acid in type II diabetic patients. Method: Red blood cell carbonic anhydrase activity was determined in washed lysed-hemolysate by the action of the enzyme on the substrate p-nitrophenyl acetate. The absorbance of released p-nitrophenol was recorded at $345 \mathrm{~nm}$. Glycated Hemoglobin was determined by ion exchange method (Spectrum Diagnostic Kit). Blood glucose, lactate, cholesterol and triglyceride were determined using Accutrend GCT meter (Roche, Germany) with cobias ${ }^{\circledR}$ test strips. Results: The present study showed that hyperglycemia significantly $(p<0.05)$ increased both erythrocyte carbonic anhydrase activity and blood lactate level in type II diabetic patients. Conclusion: We may conclude that hyperglycemia may be responsible for the increased activity of carbonic anhydrase activity and blood lactate concentration.
\end{abstract}

\section{Keywords}

Carbonic Anhydrase, Lactic Acid, Glycated Hemoglobin, Type II Diabetes

\footnotetext{
${ }^{*}$ Corresponding author.
}

How to cite this paper: Ibrahim, S.I., Amodu, A.D., Ene-Ojo, A.S., Ismaila, U.A. and Fakhruddeen, M. (2016) Effect of Hyperglycemia on Erythrocyte Carbonic Anhydrase and Lactic Acid in Type II Diabetic Subjects. Journal of Diabetes Mellitus, 6, 158-165. http://dx.doi.org/10.4236/jdm.2016.62017 


\section{Introduction}

Human erythrocytes are continuously being exposed to glucose in plasma during their circulatory life span of 120 days. The erythrocytes and their membranes have always been objects of studies as they play an important role in various physiological and metabolic events. Erythrocytes depend on the anaerobic conversion of glucose by the Embden-Meyerhof pathway for the generation of ATP. Red blood cells produce lactic acid as a byproduct of the regeneration of ATP during anaerobic glycolysis but cannot use lactic acid [1]. The rate of production can increase 50 -fold if either glucose or glycogen is required to generate ATP in the absence of oxygen $[1]$. $\mathrm{H}^{+}$transport system under conditions of exclusively aerobic metabolism is used by the cell to maintain a facilitation of $\mathrm{CO}_{2}$ diffusion, whereas under conditions of dominating anaerobic glycolysis and low intracellular $\mathrm{pH}$, it is mainly used to transport $\mathrm{H}^{+}$along with the lactate anion through the monocarboxylate transporters (MCT), a prerequisite for the elimination of lactic acid from the cell. Increasing lactate levels were associated with increased mortality [2]. Previous studies have shown that MCT-dependent lactate- $\mathrm{H}^{+}$flux is facilitated by bicarbonate transporters and carbonic anhydrase activity in various cells and tissue [3] [4].

Carbonic anhydrase - a pH regulatory enzyme catalyzes the reversible hydration of carbon dioxide and the dehydration of bicarbonate ions [5] and has been demonstrated in red blood cells, kidney, the gastrointestinal tract, and other tissues of the body. Some early evidences suggest that the changes in erythrocytes carbonic anhydrase activity may be an initial step of altered metabolism in diabetes mellitus [6] [7]. Carbonic anhydrase (CA) activities have been associated with metabolic diseases such as diabetes mellitus and hypertension [8]-[11].

Metabolic acidosis is the most common serious acid-base disorder complicating diabetes mellitus. Metabolic acidosis is associated with increased mortality [12]. Lactic acidosis results in higher mortality than metabolic acidosis of a different etiology [13]. Lactic acidosis is an alarming metabolic signal of many pathological states, and endogenous clearance of lactate is a commonly used prognostic marker of illness [14]. Shapiro et al. [15], in a study with 1278 patients with infection, demonstrated that increasing lactate levels were associated with increased mortality. Given carbonic anhydrase association with lactate flux through the MCTs in previous studies, the study aimed to investigate the effect of hyperglycemia on erythrocyte carbonic anhydrase changes in diabetes.

\section{Materials and Methods}

\subsection{Ethical Approval}

The study was approved by the Research Ethical Committee, of Kano State Hospital Management Board, Nigeria.

\subsection{Subjects}

Ten Female black African patients with type 2 diabetes and ten female black African healthy control subjects without diabetes participated in this study. The average age group of diabetic patients ranges from 25 to 50 years, average weight of 50 to $70 \mathrm{~kg}$. Dietary supplementation and lifestyle differences were not considered in this study. Blood from fasted type II diabetic patients $(\mathrm{n}=10)$ attending Diabetic Clinic at Nassarawa Specialist Hospital Kano, Nigeria was obtained. Written informed consent was obtained from all subjects after the procedure had been fully explained. Blood from fasted healthy subjects $(n=10)$ was also obtained from the Dept. of Chemistry Ahmadu Bello University, Zaria, Nigeria. Written informed consent was obtained from all subjects after the procedure had been fully explained.

\subsection{Hemolysate Preparation}

The blood samples were centrifuged at $3500 \mathrm{rpm}$ for 10 minutes. The plasma was separated from the cells and buffy coat removed. The packed red cells were washed three times with normal saline $(0.9 \% \mathrm{NaCl})$ and were lysed with ice cold water, yielding destroyed plasma membranes.

\subsection{Measurement of Erythrocyte Carbonic Anhydrase}

\section{Assay of Crude erythrocyte Carbonic Anhydrase Activity}

Carbonic anhydrase activity was determined as mentioned by vapoorte et al. [15], with the modification described by Parui et al. [8] using spectrophotometer. In this assay, the esterase activity of carbonic anhydrase was determined from the hydrolysis rate of $3 \mathrm{mM}$ p-nitrophenyl acetate to $\mathrm{p}$-nitrophenol. The assay system contained 
$100 \mu \mathrm{L}$ hemolysate placed in $1 \mathrm{~cm}$ spectrometric cell containing $1.4 \mathrm{ml} 0.05 \mathrm{M}$ Tris- $\mathrm{HCl}, \mathrm{pH}: 7.4$ and $1.5 \mathrm{ml}$ p-nitrophenyl acetate. The change in absorbance at $348 \mathrm{~nm}$ was measured over the period of $3 \mathrm{~min}$ before and after adding the sample. The absorbance was measured by a UV-Vis spectrophotometer (Shimadzu UV-2600 Spectrophotometer). One unit of enzyme activity was expressed as $\mu \mathrm{mol}$ of $\mathrm{p}$-nitrophenol relased $/ \mathrm{min} / \mu \mathrm{L}$ from hemolysate at room temperature $\left(25^{\circ} \mathrm{C}\right)[6][8]$.

\subsection{Measurement of Glycated Hemoglobin (HbA1C)}

Glycosylated haemoglobin determination: HbA1C was measured using standard reagent kits, according to the manufacturer's information (Spectrum-diagnostics, Egypt). The assay principle is based on a hemolysed preparation of whole blood mixed continuously for 5 minutes with a weakly binding cation-exchange resin. The labile fraction is eliminated during the hemolysate preparation and during the binding. During this mixing, HbA binds to the ion exchange resin leaving $\mathrm{GHb}$ free in the supernatant. After the mixing period, a filter separator is used to remove the resin from the supernatant. The percent glycosylated hemoglobin is determined by measuring absorbances at $405 \mathrm{~nm}$ of the ratio of the absorbances of the Glycosylated hemoglobin (Ghb) and the Total hemoglobin fraction $(\mathrm{THb})$. The ratio of the absorbances of $\mathrm{GHb}$ and $\mathrm{THb}$ of the control and test is used to calculate the percent $\mathrm{GHb}$ of the sample.

\subsection{Measurement of Biochemical Parameters}

Blood glucose, Blood lactate, Blood cholesterol and Blood triglycerides were measured using (Accutrend GCT Meter, Roche, Germany with Cobas ${ }^{\circledR}$ test strips)

\subsection{Statistical Analysis}

Results were presented as mean \pm standard Deviation (SD). Within and between groups, comparisons were performed by the analysis of variance (ANOVA) (using SPSS 20.0 for windows Computer Software Package). Significant differences were compared by Duncan's new Multiple Range test; a probability level of less than 5\% $(\mathrm{p}<0.05)$ was considered significant.

\section{Results}

Erythrocyte carbonic anhydrase activity was significantly higher in type II diabetic patients compared with control $\left({ }^{*} \mathrm{p}<0.05\right)$. Thus type II diabetes resulted in an increase in carbonic anhydrase activity (Figure 1). The results showed that the Glycated hemoglobin concentration increased significantly in type II diabetic patients compared with control ( ${ }^{*} \mathrm{p}<0.05$, Figure 2$)$.

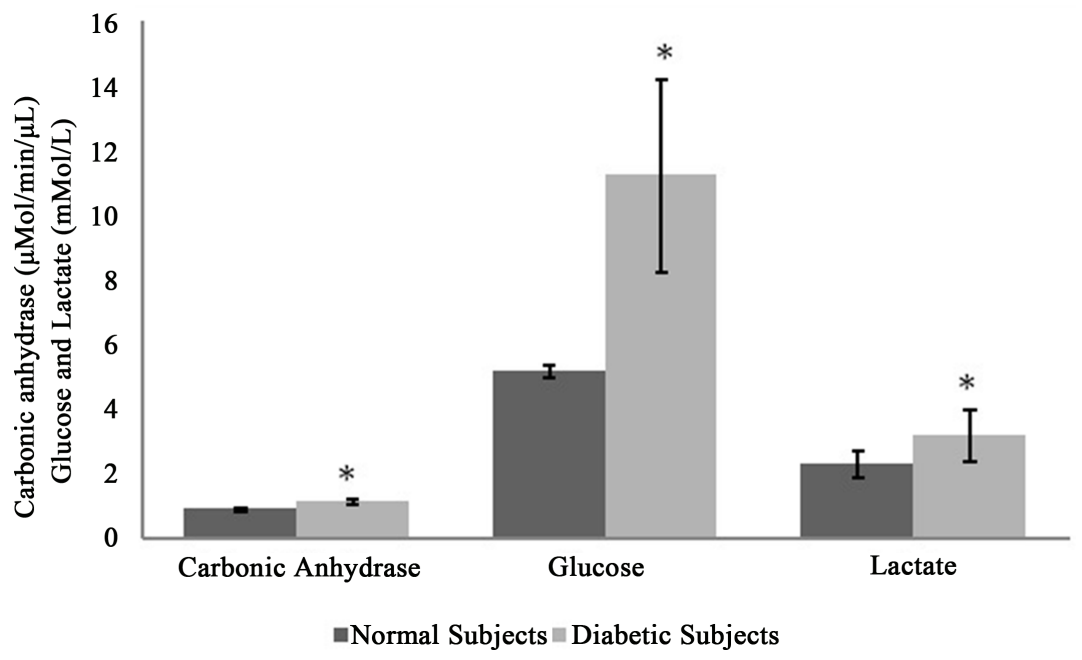

Figure 1. Erythrocyte carbonic anhydrase activity, blood glucose and blood lactate from type II diabetic patients on Metformin drug therapy. ${ }^{*} \mathrm{p}<0.05$ vs Normal subjects, $(\mathrm{n}=10)$. 


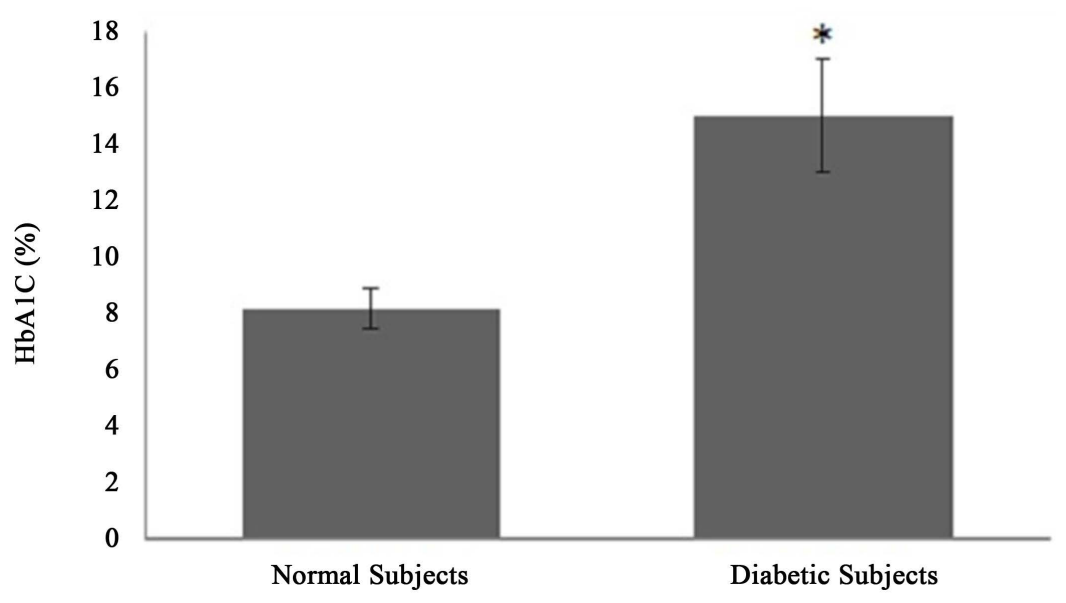

Figure 2. HbA1c (\%) concentration in type II diabetic patients on metformin drug therapy. *p < 0.05 vs Normal subjects, $(n=10)$.

The glucose and lactate levels were significantly higher in type II diabetic patient compared to controls ${ }^{*} \mathrm{p}<$ 0.05, Figure 1). Similarly the levels of cholesterol and triglycerides were significantly increased in type II diabetic patients when compared with the controls $\left({ }^{*} \mathrm{p}<0.05\right.$, Figure 3 ). Bivariate analysis showed no significant correlation between erythrocyte carbonic anhydrase with either glycated hemoglobin, glucose or with lactate in human diabetic subjects.

\section{Discussion}

Our data indicate that hyperglycemia results in increase in both carbonic anhydrase activity and blood lactate level. Our data suggest that the increased activity of carbonic anhydrase may be primarily the result of increased intracellular lactate level due to increased anaerobic conversion of glucose to lactate. This implies that diabetic condition that increased blood glucose concentration induces increased glycolytic rate in the erythrocytes and consequently increases the concentration of lactate which induces increases carbonic anhydrase activity. Since erythrocytes depend on the anaerobic conversion of glucose by the Embden-Meyerhof pathway for the generation of ATP. Red blood cells produce lactic acid as a byproduct of the regeneration of ATP during anaerobic glycolysis but cannot use lactic acid [1]. Lactate is transported out of the cell via monocarboxylate transporters (MCT) in an electroneutral transport mode of $1 \mathrm{H}^{+}$: 1 Lactate [16]. It has been reported that MCT dependent lactate- $\mathrm{H}^{+}$flux is facilitated by bicarbonate transporters and carbonic anhydrase (CA) activity in various cells and tissues [3] [4] [17] [18]. Our findings are consistent with recent studies in STZ induced diabetes (which is a model of type 1 diabetes) that resting blood lactate is reported to be elevated [19] [20]. However, some early evidences suggest that the changes in carbonic anhydrases activities in erythrocytes may be an initial step of altered metabolism in diabetes mellitus [6]. It has been reported that MCT1 and MCT4 transport activity is increased by interaction with carbonic anhydrase II (CAII) [4] [18] [21].

Hyperglycemia may lead to increased blood lactate accumulation, as a result of increased erythrocyte glycolytic rate for the regeneration of ATP; this in turn may lead to increased carbonic anhydrase activity to facilitate lactate out-flux into plasma to prevent intracellular lactate accumulation. Both increased lactate and increased carbonic anhydrase activity may result in decreased $\mathrm{pH}$. Low $\mathrm{pH}$ has been reported to increase glycation of hemoglobin. Decreased $\mathrm{pH}$ has also been shown to reduce $\mathrm{O}_{2}$ binding to hemoglobin $(\mathrm{Hb})$ which leads to hypoxia. Hypoxia stimulates erythrocyte anaerobic ATP production, which produces lactate as the end product. Lactate must be shuttle out of the cell via the MCT's; facilitated by carbonic anhydrase to prevent intracellular lactate accumulation. Thus may also result in increased carbonic anhydrase activity.

We hypothesize that (Figure 4) the increased lactate efflux from erythrocyte in diabetic subjects may reflect the mass-action effect of higher intracellular lactate concentration. This mass action of lactate may account for the increased activity of carbonic anhydrase that facilitate lactate efflux from the erythrocyte of diabetic subjects into the plasma when compared to non-diabetic subjects. We may therefore report that increased gluconeogenesis in diabetic subjects may be the result of increased carbonic anhydrase activity that facilitate lactate (gluconeogenic 


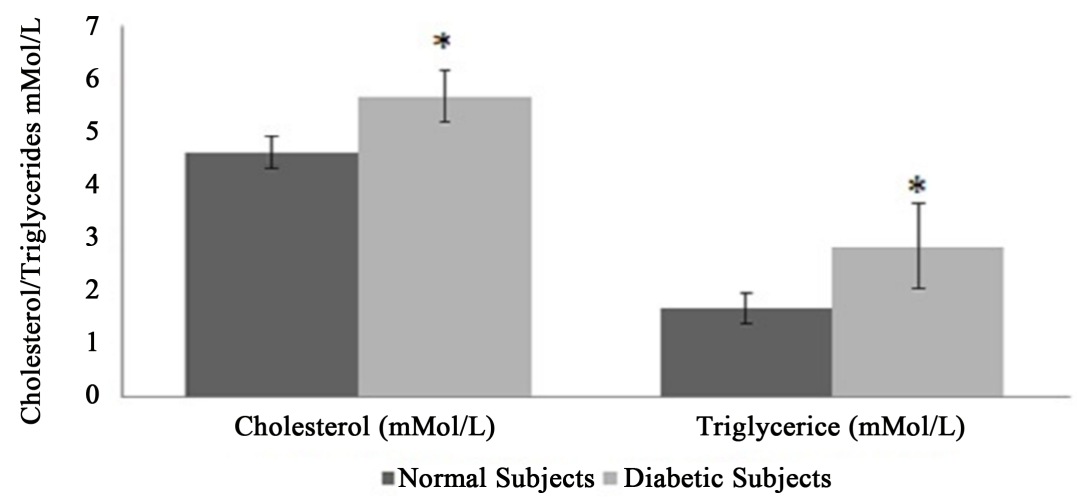

Figure 3. Blood cholesterol and triglyceride level in type II diabetic patients on metformin drug therapy. ${ }^{*} \mathrm{p}<0.05$ vs Normal subjects, $(\mathrm{n}=10)$.

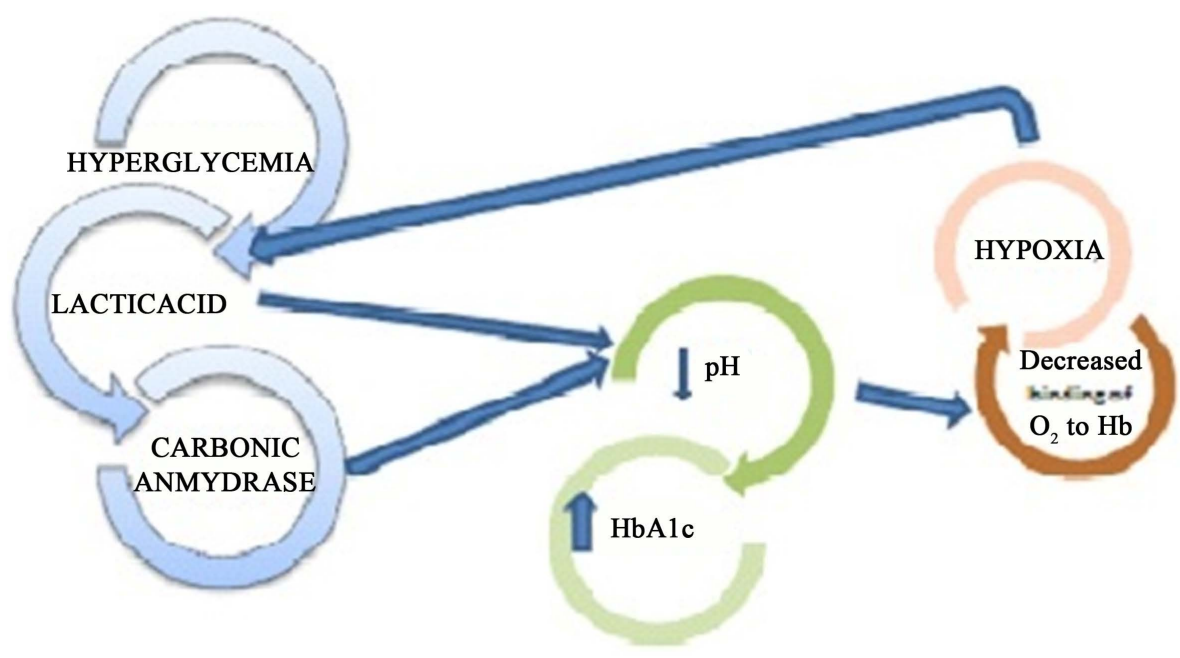

Figure 4. Hypothetical model of hyperglycemia induced carbonic anhydrase activity increase in type II diabetes mellitus.

precursor) uptake by the liver cells. Previous studies indicate that gluconeogenesis is increased in NIDDM [22] [23].

Gluconeogenesis could be increased in NIDDM because of greater delivery of gluconeogenic substrates to the liver, greater efficiency of hepatic uptake, and conversion of these substrates into glucose, or a combination of these processes. Increased rates of cori cycle have been observed in diabetic dogs [24] and have also been suggested in diabetic humans [25]. Zawadzki et al. [26] concluded that the rates of endogenous glucose production and the Cori cycle are increased in subjects with NIDDM.

Our results are consistent with the findings of Young et al. [27] who reported an association between lactate, adiposity and type 2 diabetes. In a longitudinal analysis of Swedish men, elevated serum lactate was associated with a 2.4-fold higher incidence of type 2 diabetes [28]. Kondo et al. [6] found that levels of both CA-I and CA-II in human erythrocytes in patients with diabetes mellitus were increased by $17.7 \%$ and $15 \%$, respectively. They suggested that exposure of erythrocytes to high concentrations of glucose results in an increase in the concentrations of the enzymes in red cells.

Our results suggest that lactate: $\mathrm{H}^{+}$exiting the cell via MCTs accumulates in the plasma which leads to the dissipation of the $\mathrm{H}^{+}$gradient and, hence, lactic acidosis which further reduced lactate transport. This in turn may result in intracellular acidosis due to accumulation of intracellular lactate. Low intracellular $\mathrm{pH}(\mathrm{pHi})$ has been reported to increase glycation of hemoglobin as $\mathrm{pH}$ levels within the erythrocyte can increase (low erythrocyte $\mathrm{pH}$ ) or decrease (high erythrocyte $\mathrm{pH}$ ) HbA1c formation [29].

Several factors have been reported that can influence the rate of glycation of hemoglobin: $\mathrm{pH}$ [30]-[32], glucose 
concentration (Higgins and Bunn, 1981), carbonate [33] and catalysis by 2,3-diphosphoglycerate [31] [34]-[36]. We may suggest that increased HbAlc level seen in diabetic subjects may be attributed to decreased $\mathrm{pH}_{\mathrm{i}} \mathrm{due}_{\mathrm{e}}$ decreased lactate efflux probably as a result of fall in extracellular $\mathrm{pH}$ due to lactate accumulation. In the present study our results showed significant increase in both total cholesterol and triglyceride level $(p<0.05)$. Diabetic dyslipidemia is associated with high plasma triglycerides, low HDL-Cholesterol and increased small dense LDL-Cholesterol particles [37]. Hypertriglyceridemia is more common in diabetics as compared to non-diabetics due to four (4) fold increase in VLDL triglyceride [38].

\section{Conclusion}

Diabetes may therefore be responsible for the increased activity of carbonic anhydrase, which may come as a result of increased rate of glycolysis in the erythrocyte producing higher lactate that needs to be removed to prevent intracellular lactate accumulation that may lead to drop in intracellular $\mathrm{pHi}$.

\section{Acknowledgements}

We would like to acknowledge the staffs of diabetic clinic Mohammed Abdullahi Wase Nassarawa specialist Hospital Kano, particularly Dr. Fakhrudden Mohammed for their guidance and support.

\section{Author Contributions}

All authors contributed equally to this work. Ibrahim S. Ismail carried out the studies reviewed the literature and wrote the preliminary manuscript. Ameh D. Amodu, Atawodi S. Ene-Ojo and Umar I. Alhaji supervised the project, made the final revisions and revised the preliminary manuscript, and Mohammed Fakhruddeen participated in the clinical study.

\section{Conflict of Interests}

We declare no competing interests.

\section{References}

[1] Luft, F.C. (2001) Lactic Acidosis Update for Critical Care Clinicians. Journal of the American Society of Nephrology, 12, S15-S19.

[2] Shapiro, N.I., Howell, M.D. and Talmor, D. (2005) Serum Lactate as a Predictor of Mortality in Emergency Department Patients with Infection. Annals of Emergency Medicine, 45, 524-528. http://dx.doi.org/10.1016/j.annemergmed.2004.12.006

[3] Becker, H.M., Broer, S. and Deitmer, J.W. (2004) Facilitated Lactate Transport by MCT1 When Co-expressed with the Sodium Bicarbonate Cotrans-Porter (NBC) in Xenopus Oocytes. Biophysical Journal, 86, 235-247. http://dx.doi.org/10.1016/S0006-3495(04)74099-0

[4] Becker, H.M. and Deitmer, J.W. (2008) Nonenzymatic Proton Handling by Carbonic Anhydrase II during $\mathrm{H}^{+}$-Lactate Cotransport via Monocarboxylate Transporter 1. The Journal of Biological Chemistry, 283, 21655-21667. http://dx.doi.org/10.1074/jbc.M802134200

[5] Carter, M.J. and Parsons, D.S. (1971) The Isoenzymes of Carbonic Anhydrase: Tissue, Subcellular Distribution and Functional Significance, with Particular Reference to the Intestinal Tract. The Journal of Physiology, 215, 71-94. http://dx.doi.org/10.1113/jphysiol.1971.sp009458

[6] Gambhir, K.K., Oates, P., Verma, M., Temam, S. and Cheatham, W. (1997) High Fructose Feeding Enhances Erythrocyte Carbonic Anhydrase 1mRNA Levels in Rat. Annals of the New York Academy of Sciences, 827, 163-169. http://dx.doi.org/10.1111/j.1749-6632.1997.tb51831.x

[7] Kondo, T., Murakami, K., Ohtsuka, Y., Tsuji, M., Gasa, S., Taniguchi, N. and Kawakami, Y. (1987) Estimation and Characterization of Glycosylated Carbonic Anhydrase I in Erythrocytes from Patients with Diabetes Mellitus. Clinica Chimica Acta, 116, 227-236. http://dx.doi.org/10.1016/0009-8981(87)90425-6

[8] Parui, R., Gambir, K.K., Cruz, I. and Hosten, A.O. (1992) Erythrocyte Carbonic Anhydrase: A Major Intracelluler Enzyme to Regulate Cellular Sodium Metabolism in Chronic Renal Failure Patients with Diabetes and Hypertension. International Journal of Biochemistry, 26, 809-820.

[9] Tashian, R.E., Hewett-Emmet, D. and Venta, P.J. (1991) Diversity and Evolution in the Carbonic Anhydrase Gene 
Family. In: Botrè, F., Gros, G. and Storey, B.T., Eds., Carbonic Anhydrase: From Biochemistry and Genetics to Physiology and Clinical Medicine, VCH Verlagsgesellschaft, Weinheim, 151-161.

[10] Wistrand, P.J. and Lindqvist, A. (1991) Design of Carbonic Anhydrase Inhibitors and the Relationship between the Pharmacodynamics and Pharmacokinetics of Acetazolamide. In: Botrè, F., Gros, G. and Storey, B.T., Eds., Carbonic Anhydrase: From Biochemistry and Genetics to Physiology and Clinical Medicine, VCH Verlagsgesellschaft, Weinheim, 352-374.

[11] Parui, R., Gambir, K.K. and Mehrotra, P.P. (1991) Changes in Carbonic Anhydrase May Be the Initial Step of Altered Metabolism in Hypertension. International Journal of Biochemistry, 23, 779-789.

[12] Celik, U., Celik, T., Avci, A., Annagur, A., Yilmaz, H.L., Kucukosmanoglu, O., Topaloglu, A.K. and Daglioglu, N. (2009) Metabolic Acidosis in a Patient with Type 1 Diabetes Mellitus Complicated by Methanol and Amitriptyline Intoxication. European Journal of Emergency Medicine, 16, 45-48. http://dx.doi.org/10.1097/MEJ.0b013e3283034245

[13] Gunnerson, K.J., Saul, M., He, S. and Kellum, J.A. (2006) Lactate versus Non-Lactate Metabolic Acidosis: A Retrospective Outcome Evaluation of Critically Ill Patients. Critical Care, 10, R22.

[14] Nguyen, H.B., Rivers, E.P. and Knoblich, B.P. (2004) Early Lactate Clearance Is Associated with Improved Outcome in Severe Sepsis and Septic Shock. Critical Care Medicine, 32, 637-1642. http://dx.doi.org/10.1097/01.CCM.0000132904.35713.A7

[15] Verpoorte, J.A., Mehta, S. and Edsall, J.T. (1967) Esterase Activities of Human Carbonic Anhydrase. The Journal of Biological Chemistry, 242, 4221-4229.

[16] Klier, M., Andes, T.F., Deitmer, J.W. and Becker, H.M. (2014) Intracellular and Extracellular Carbonic Anhydrases Cooperate Non-Enzymatically to Enhance Activity of Monocarboxylate Transporters. The Journal of Biological Chemistry, 289, 2765-2775. http://dx.doi.org/10.1074/jbc.M113.537043

[17] Wetzel, P., Hasse, A., Papadopoulos, S., Voipio, J., Kaila, K. and Gros, G. (2001) Extracellular Carbonic Anhydrase Activity Facilitates Lactic Acid Transport in Rat Skeletal Muscle Fibres. The Journal of Physiology, 531, 743-756. http://dx.doi.org/10.1111/j.1469-7793.2001.0743h.x

[18] Becker, H.M., Hirnet, D., Fecher-Trost, C., Sultemeyer, D. and Deitmer, J.W. (2005) Transport Activity of MCT1 Expressed in Xenopus Oocytes Is Increased by Interaction with Carbonic Anhydrase. The Journal of Biological Chemistry, 280, 39882-39889. http://dx.doi.org/10.1074/jbc.M503081200

[19] Py, G., Lambert, K., Milhavet, O., Eydoux, N., Prefaut, C. and Mercier, J. (2002) Effects of Streptozotocin Induced Diabetes on Markers of Skeletal Muscle Metabolism and Monocarboxylate Transporter 4 Transporters. Metabolism, 51, 807-813. http://dx.doi.org/10.1053/meta.2002.33343

[20] Enoki, T., Yoshida, Y., Hatta, H. and Bonen, A. (2003) Excersice Training Alleviates MCT1 and MCT4 Reductions in Heart and Skeletal Muscle of STZ Induced Diabetic Rats. Journal of Applied Physiology, 94, 2433-2438. http://dx.doi.org/10.1152/japplphysiol.01155.2002

[21] Becker, H.M., Klier, M. and Deitmer, J.W. (2010) Nonenzymatic Augmentation of Lactate Transport via Monocarboxylate Transporter Isoform 4 by Carbonic Anhydrase II. The Journal of Membrane Biology, 234, 125-135. http://dx.doi.org/10.1007/s00232-010-9240-y

[22] Consoli, A., Nurjhan, N., Capani, F. and Gerich, J. (1989) Predominant Role of Gluconeogenesis in Increased Hepatic Glucose Production in NIDDM. Diabetes, 38, 550-557.

[23] Kreisberg, R. (1972) Glucose-Lactate Inter-Relations in Man. The New England Journal of Medicine, 287, $132-137$.

[24] Stevenson, R.W., Parsons, J.A., George, K. and Alberti, K.G.M.M. (1983) Effect of Intraportal and Peripheral Insulin in Glucose Turnover and Recycling in Diabetic Dogs. American Journal of Physiology, 244, E190-E195.

[25] Reichard Jr., G.A., Moury, N.F., Hochella, N.J., Patterson, A.L. and Weinhouse, S. (1963) Quantitative Estimation of the Cori Cycle in the Human. The Journal of Biological Chemistry, 238, 495-501.

[26] Zawadski, J., Wolfe, R., Mott, D., Lillioja, S., Howard, B. and Bogardus, C. (1988) Increased Rate of Cori Cycle in Obese Subjects with NIDDM and Effects of Weight Reduction. Diabetes, 37, 154-159.

http://dx.doi.org/10.2337/diab.37.2.154

[27] Hunter, Y.J., Crawford, S.O., Hoogeveen, R.C., Brancati, F.L., Astor, B.C., Ballantyne, C.M. and Schmidt, M.I. (2010) Association of Blood Lactate with Type 2 Diabetes: The Atherosclerosis Risk in Communities Carotid MRI Study. International Journal of Epidemiology, 39, 1647-1655. http://dx.doi.org/10.1093/ije/dyq126

[28] Ohlson, L.O., Larsson, B., Bjorntorp, P., et al. (1988) Risk Factors for Type 2 (Non-Insulin-Dependent) Diabetes Mellitus. Thirteen and One-Half Years of Follow-Up of the Participants in a Study of Swedish Men Born in 1913. Diabetologia, 31, 798-805. http://dx.doi.org/10.1007/BF00277480

[29] Speeckaert, M., Van Biesen, W., Delanghe, J., Slingerland, R., Wiecek, A., Heaf, J., Drechsler, C., Lacatus, R, Vanholder, R., Nistor, I. and for the European Renal Best Practice Guideline Development Group on Diabetes in Advanced 
CKD (2014) Are There Better Alternatives than Haemoglobin A1c to Estimate Glycaemic Control in the Chronic Kidney Disease Population? Nephrology Dialysis Transplantation, 1-11.

[30] Higgins, P. and Bunn, H. (1981) Kinetics Analysis of Nonenzymatic Glycosylation of Hemoglobin. The Journal of Biological Chemistry, 256, 5204-5208.

[31] Lowrey, C., Lyness, S. and Soeldener, J. (1985) The Effect of Hemoglobin Ligands on the Kinetics of Human Hemoglobin Formation. The Journal of Biological Chemistry, 260, 11611-11618.

[32] Gil, H., Mata-Sagreda, J. and Schowen, R. (1991) Isotope Effects in the Nonenzymatic Glucation of Hemoglobin Catalyzed by Phosphate. Actualidades de Fisicoquímica Orgánica, 1, 286-306.

[33] Gil, H., Vásquez, B., Peña, M. and Uzcategui, J. (2004) Effect of Carbonate and Arsenate on the Kinetics of Glycation of Human Hemoglobin. Journal of Physical Organic Chemistry, 17, 537-540. http://dx.doi.org/10.1002/poc.772

[34] Gil, H. and Uzcategui, J. (1993) Isotope Effects in the Nonenzymatic Glycation of Hemoglobin Catalyzed by DPG. Actualidades de Fisicoquímica Orgánica, 1, 109-121.

[35] Baynes, J., Thorpe, S. and Murtiashaw, M. (1984) Nonenzymatic Glucosylation of Lysine Residues in Albumin. Methods in Enzymology, 106, 88-98. http://dx.doi.org/10.1016/0076-6879(84)06010-9

[36] Smith, R., Koenig, R., Arjen, A., Soeldner, J. and Aoki, T. (1982) Regulation of Hemoglobin A1C Formation in Human Erythrocytes in Vivo. Journal of Clinical Investigation, 69, 1164-1168. http://dx.doi.org/10.1172/JCI110552

[37] Mooradian, A.D. (2009) Dyslipidemia in Type 2 Diabetes Mellitus. Nature Clinical Practice Endocrinology \& Metabolism, 5, 150-159. http://dx.doi.org/10.1038/ncpendmet1066

[38] Arbeeny, C.M., Nordin, C., Edelstein, D., Stran, N., Gibbons, N. and Eder, H.A. (1989) Hyperlipoproteinimia in Spontaneously Diabetic, Guinea Pigs. Metabolism, 38, 895-900. http://dx.doi.org/10.1016/0026-0495(89)90238-2 